\title{
FOUCAULT E A GENEALOGIA DO ESTADO MODERNO
}

\author{
Foucault and the Genealogy of Modern State
}

Helton Adverse *

Resumo: O objetivo deste artigo é apresentar as linhas gerais da "genealogia do Estado moderno" de Foucault. Para tanto, vamos dar especial atenção a dois momentos de seu percurso investigativo. No primeiro momento, entre 1972 e 1976, o Estado aparece como a instituição emblemática onde se exerce o poder jurídico-político. A partir de 1978, o Estado é abordado sob outra perspectiva, sendo definido como uma "prática de governo". No final do texto, fazemos uma breve inquirição sobre as limitações e possibilidades abertas por essa genealogia, assinalando que não se trata, em absoluto, de relegar a questão do Estado ao abandono, mas de mostrar que ela é redimensionada pela genealogia do poder.

Palavras-chave: Foucault. Genealogia. Estado. Soberania. Governamentalidade.

Abstract: The main purpose of this paper is to present the general lines of Foucault's "genealogy of the modern State", giving special attention to two moments of his investigative trajectory. In the first moment, between 1972 and 1976, the state is the emblematic institution where the sovereign power is exercised. In 1978, the State is approached from another perspective, being defined as a "government practice". At the end of the text, we briefly inquire about the limitations and possibilities opened by this genealogy, noting that it is not a question of relegating the State to abandonment, but of showing that it is resized by the genealogy of power.

Key-words: Foucault. Genealogy. State. Sovereignty. Governmentality.

* Doutor em Filosofia (UFMG). Pós-Doutorado em Filosofia (EHESS). Professor Associado do Departamento de Filosofia da UFMG. Gostaria de agradecer aos pareceristas anônimos cujas observações contribuíram significativamente para o aprimoramento deste trabalho. Artigo enviado em 05/02/2018 e aprovado para publicação em 18/07/2018. 


\section{Introdução}

$\mathrm{O}$ problema do Estado no pensamento de Michel Foucault tem recebido atenção no âmbito de sua recepção crítica mais recente. Ao menos três estudos (SAWYER, 2015; SKORNICKI, 2015; DEAN e VILLADSEN, 2016), publicados nos últimos anos, colocaram no centro de suas análises a concepção foucaultiana de Estado, identificando em Foucault um posicionamento fortemente crítico frente ao conceito tradicional do Estado como agente privilegiado na vida política. Apesar desses intérpretes diferirem no que concerne à relação de Foucault com o Estado (Sawyer e Skornicki amenizam seu ímpeto anti-estatista, ao passo que Dean e Villadsen preferem mostrar que Foucault não é capaz de se liberar totalmente de uma postura anti-estatista, apesar de não ser vítima da "fobia de Estado" que denuncia), todos eles insistem na necessidade de reconsiderar o papel do Estado a partir da genealogia do poder empreendida por Foucault. De nossa parte, propomos uma abordagem um pouco diferente. A colocação do problema em termos de "estatismo" ou "anti-estatismo" não nos parece muito apropriada (embora façamos referência a isso no final do artigo), porém estamos de pleno acordo a respeito da relevância da genealogia foucaultiana para a reflexão sobre o Estado. $\mathrm{O}$ caminho que pretendemos seguir visa chamar a atenção para o fato de Foucault, sem jamais tomar diretamente o Estado como seu objeto de análise, realizar uma espécie de "analítica do Estado" em dois níveis: o primeiro poderia ser denominado de "epistemológico", onde o Estado perde sua autonomia como objeto de investigação teórica; o segundo nível seria propriamente "político", onde o Estado deixa de se constituir como o lugar privilegiado do agenciamento político na medida em que o poder estatal não é mais considerado a forma por excelência do poder político. Em outras palavras, na genealogia do poder, o Estado deixa de fornecer a chave para a compreensão do político. Contudo, longe de significar seu abandono teórico, isso produz um redimensionamento do lugar do Estado na política, como pretendemos demonstrar.

Veremos que a análise do Estado parece imprescindível para a compreensão das relações de poder na sociedade moderna. Este é o problema que queremos investigar nesse artigo, mas, de início, é preciso esclarecer o que justifica o exame do problema do Estado na analítica do poder. Para entender esse ponto, convém lembrar que essa analítica se situa no domínio do exercício do poder, quer dizer, no registro em que ele se faz presente na existência cotidiana das pessoas. Sempre interessou a Foucault tomar o problema do poder nesse nível "existencial", isto é, "analisar aquilo que se passa cotidianamente nas relações de poder" (FOUCAULT, 1994e, p. 541), pois é onde nós sentimos efetivamente sua presença sobre nossas vidas. Ora, o tipo de análise do poder realizado pela teoria política clássica, que privilegia a figura do Estado e 
desenha uma topografia política claramente hierárquica, deixa de fora a presença maciça do poder nesse campo em que nos constituímos como sujeitos históricos. Dizendo de outro modo, as "teorias do Estado" e sua concomitante representação do poder jurídico-política não são capazes de capturar "a maneira como o poder se exerceu e se exerce" (FOUCAULT, 1976, p. 116) ou, como afirmou recentemente Daniele Lorenzini, "os tratados modernos e contemporâneos de filosofia política continuaram em grande parte capturados por essa representação que, no entanto, não está e jamais esteve em conformidade com a realidade do exercício do poder" (LORENZINI, 2017, p. 216). Quando Foucault propõe, em uma conferência no Japão em 1978, que a filosofia se ocupe "de tornar visível o que é visível", de "fazer ver o que vemos" (FOUCAULT, 1994e, p. 541), ele está indicando de modo claro que as formas tradicionais de filosofia política mascaram a realidade do poder, impedem de ver o que ele é "em sua essência", quer dizer, a maneira como é efetivamente exercido. Por isso, é imprescindível, de seu ponto de vista, fazer a crítica das teorias políticas que reduzem o problema do político às questões do Estado, ou que identificam o político com o Estatal. Aliás, ele já afirmava no curso de 1976 - Em defesa da sociedade - que a representação do poder político em termos jurídicos (ou ainda, a compreensão do poder na chave da soberania) cumpre precisamente a função de mascarar seus efeitos de dominação (FOUCAULT, 1997, p. 33) e, no mesmo ano, no primeiro volume da História da sexualidade, ele dizia que é "sob a condição de esconder uma parte de si mesmo que o poder é tolerável" ou, ainda, que o sucesso de seu funcionamento "é proporcional ao que ele consegue esconder de seus mecanismos" (FOUCAULT, 1976, p. 113). Isso significa que fazer a crítica do Estado como a sede do poder soberano integra o projeto de uma genealogia do poder e que o privilégio epistemológico que lhe é tradicionalmente concedido pela filosofia política é mais um obstáculo à explicitação das relações de poder, além de mascarar sua verdadeira natureza. Parece-nos ser este o pano de fundo da análise foucaultiana do Estado. Resta-nos, agora, passar em exame o modo como ele a realiza.

Antes de fazê-lo, lembramos novamente que o Estado como tal não é um tema de investigação para Foucault e que estava longe de seus propósitos elaborar algo como uma "teoria do Estado". Pelo contrário, seu objetivo, como acabamos de indicar, era sobretudo fazer uma análise das relações de poder que colocasse em questão a centralidade do Estado, conferida seja pelas teorias tradicionais que operam com a noção de soberania (por vezes denominadas por Foucault de "discurso jurídico-filosófico") seja pela tradição do marxismo. Ora, essa analítica do poder deveria mostrar a insuficiência de sua identificação com um centro, um lugar privilegiado no qual ele fosse produzido e a partir do qual se disseminasse: contra a unidade do poder, Foucault enfatiza sua multiplicidade, sua microfísica, sua capilaridade e sua 
imanência aos domínios onde ele é exercido ${ }^{1}$. O poder, repetirá Foucault em diversas ocasiões, então, "vem de baixo". Levando isso em conta, torna-se necessário esclarecer como o problema do Estado se coloca inicialmente na obra de Foucault, quer dizer, nessa primeira metade dos anos 1970. Somente após ter realizado esse movimento é possível apreender plenamente o sentido daquilo que ele vai denominar - não sem reticências - em 1978 de uma "genealogia do Estado moderno" (FOUCAULT, 2004a, p. 362).

\section{Uma Primeira Abordagem do Estado}

No curso ministrado no Collège de France em 1971-1972, Teorias e instituições penais, o Estado aparece como elemento importante para se compreender a configuração das relações entre poder e saber a partir do século XVII. A primeira metade do curso é dedicada ao estudo da revolta dos $\mathrm{Nu-pieds} \mathrm{e}$ visa delimitar o momento em que as práticas jurídicas sofrem uma profunda alteração: elas deixam de ser localizadas na própria sociedade em favor de sua confiscação pelo Estado. O Estado moderno surge em um contexto de centralização do poder e dos aparelhos repressivos, que se incidem sobretudo sobre o campo da justiça e da economia. Mais propriamente, a revolta dos $\mathrm{Nu}$-pieds permite a Foucault mostrar o nascimento da justiça como aparelho repressivo do Estado, que implementa um sistema de repressão que "não tem mais a função de assegurar, como na Idade Média, a circulação das riquezas, mas a repressão das sedições populares pela segregação dos homens" (FOUCAULT, 2015, p. 260). Em suma, o Estado detém o monopólio da justiça e da fiscalidade por meio de um aparato repressivo, fórmula que, aparentemente, pouco destoa das teses defendidas no âmbito da tradição marxista e daquelas formuladas pelas ciências sociais contemporâneas (Weber). Contudo, para não perdermos de vista o sentido da análise de Foucault, temos de prestar atenção ao seguinte ponto: a implementação desse aparelho repressivo não deve ser tratada como um efeito das relações de produção que visa somente assegurar sua consolidação. O Estado e os aparelhos ideológicos não podem ser devidamente compreendidos se forem reduzidos à superestrutura. A esse respeito, a aula de 23 de fevereiro de 1972 é bastante esclarecedora:

É talvez verdadeiro que as formas jurídicas (ao mesmo tempo os princípios de direito e as regras de procedimento) traduzam, exprimam relações econômicas. É talvez verdadeiro que as decisões de justiça tenham essencial-

\footnotetext{
${ }^{1}$ Vale lembrar aqui a famosa passagem de $A$ vontade de saber: "Por poder, parece-me que é preciso entender de início a multiplicidade das relações de força que são imanentes ao domínio onde elas se exercem e são constitutivas de sua organização" (1976, p. 121). Nesse contexto, recorda Lagasnerie, "tornar inteligível o exercício do poder até seus efeitos mais periféricos impõe desde então fabricar um ponto de vista que não atribua residência ao poder, que não suponha a existência de um 'ponto central', de um 'lugar único' a partir dos quais seriam propagados os mecanismos de controle" (2015, p. 4).
} 
mente por papel reconduzir as relações de produção. Existe, entretanto, um outro nível onde se revela o funcionamento do aparelho judiciário. Nesse nível, ele não é expressão nem recondução das relações econômicas. Ele se inscreve como relação de poder nas relações econômicas, e as modifica por isso mesmo: ele transcreve as relações econômicas nas relações de poder e as modifica por isso mesmo. Um aparelho como o aparelho judiciário não é somente expressão ou instrumento de reprodução. Ele é um dos sistemas pelos quais se faz o investimento do político pelo econômico, a inserção do político no econômico. Ele assegura ao mesmo tempo a onipresença do político ao econômico e o deslocamento (décalage) de um a outro (FOUCAULT, 2015, pp. 171-2).

Não é difícil perceber aqui o alvo imediato das críticas de Foucault - isto é, o marxismo e particularmente sua nova interpretação empreendida por Louis Althusser ${ }^{2}$ - mas o mais importante é reter a concepção do poder e do político que aí é veiculada. Vale a pena citar o trecho que vem logo na sequência:

No estudo de um aparelho de Estado, é preciso sem dúvida distinguir: sua estrutura, que é de natureza repressiva; sua estratégia (a estratégia de suas decisões) que é orientada para a reprodução; e seu funcionamento como aparelho que mantém o jogo das relações de poder e das relações de produção uns em relação aos outros (FOUCAULT, 2015, p. 172).

Esse trecho é acompanhado da seguinte nota: "as relações de poder não se sobrepõem às relações econômicas. Eles formam com elas uma trama única. As relações de poder são tão profundas quanto as relações de produção. Elas não são deduzidas umas da outras. Elas reconduzem umas às outras" (FOUCAULT, 2015, p. 172).

Na perspectiva de Foucault, as relações de poder são, por um lado, irredutíveis à relações econômicas. Por outro lado, elas desempenham um papel fundamental na configuração destas últimas. Ora, isso significa que as relações de poder são constitutivas do político, ao mesmo tempo em que estão profundamente enraizadas nas relações de produção. Por isso B. Harcourt pode dizer que as relações de poder são compreendidas como as "verdadeiras condições de formação e de transformação dos modos de produção, quer seja na constituição do homem como 'força de trabalho' ou no processo de acumulação e circulação de riquezas" 3 .

Se a esfera política não pode estar simplesmente subordinada ao econômico, se os mecanismos de poder não são simplesmente instrumentos de reprodução das relações de produção, o político parece cumprir em Foucault uma função constitutiva que determina sua imbricação com o econômico e com o jurídico. Mas qual seria, especificamente, essa função? Para res-

${ }^{2}$ A respeito ver a carta de E. Balibar anexada à edição do curso (FOUCAULT, 2015, p. 285-9).

${ }^{3}$ B. Harcourt, nota 10 da aula de 23 de fevereiro (FOUCAULT, 2015, p. 177-8). 
ponder a essa questão, temos de voltar à formulação acima segundo o qual o Estado reprime pela segregação dos homens.

A maneira de operar típica do Estado moderno é aquela da diferenciação, como vemos no episódio da revolta dos Nu-pieds. Essa diferenciação consiste em uma separação primeiramente entre o justo e o injusto, entre o permitido e o proibido e, por fim, entre os próprios homens, como vemos exemplificado pela atitude de Séguier. Com efeito, o representante do rei enviado para pôr fim à revolta exerce para todos aqueles que com ela se envolveram, direta ou indiretamente, o papel de um juiz que determina quem merece o perdão e quem merece ser condenado. Para Foucault, aí se manifesta algo da própria natureza do poder soberano: "O poder quer ser reconhecido no papel daquele que separa e diferencia, que perdoa a uns e não a outros, que se apoia sobre alguns e ataca outros (...) É o poder que fará a distinção entre bons e maus, culpados e inocentes" (FOUCAULT, 2015, p. 50).

Essa forma de exercício do poder ganha contornos muito precisos no contexto da formação do Estado: reclamando o poder de discriminar, o Estado moderno será aquele que implementará o grande Encarceramento, a forma institucionalizada da separação entre o legal e o ilegal, o moral e o imoral, o delinquente e o bom cidadão, o socialmente aceitável e aquilo que deve ser retirado do convívio social. Evidentemente, o tema não é novo em Foucault, remontando à História da loucura, mas aqui interessa chamar a atenção para o fato do Encarceramento significar uma divisão no espaço social operada pelo poder político. Essa divisão corresponde a uma organização, à criação de um espaço de "ordem", que é a função precípua do Estado. Aliás, é exatamente nesses termos que Foucault irá definir o Estado moderno em comparação com o domínio medieval:

Ele é o lugar de uma ordem econômica, militar e legislativa; e por conseguinte se define um novo personagem do rei: ele não é mais o suserano ou o soberano, ele é o guardião da ordem, de uma ordem pública caracterizada pelo controle centralizado das armas, pela segurança da troca mercantil, pela obediência às prescrições do soberano (FOUCAULT, 2015, p. 185).

O Estado como espaço da ordem manifesta não uma infraestrutura econômica subjacente que determinaria seu sentido, mas relações de forças que o estruturam. Por conseguinte, o papel do Estado, neste momento inicial da analítica do poder - momento no qual Foucault ainda não havia feito a crítica da concepção do poder em termos estritamente "negativos" e por isso ainda se atém a uma concepção repressiva do poder do Estado - não é devidamente compreendido sem a referência a esses elementos que o transcendem, àquilo que nessa ocasião ele denomina de uma "dinástica das forças":

Nessas cenas de manifestação do poder [a reação à revolta dos Nu-pieds], quais são os papéis, quais gestos são feitos, quais discursos proferidos? O 
que é dito ou, antes, o que aí se encontra manifesto? Pois essas cerimônias, ritos, gestos, não querem dizer nada. Eles não decorrem de uma semiologia, mas de uma análise das forças (de seu jogo, de sua estratégia). As marcas que aí aparecem não devem ser analisadas [através] de uma semiótica dos elementos, mas de uma dinástica das forças (FOUCAULT, 2015, p. 47).

O termo "dinástica" foi a primeira opção de Foucault para denominar a analítica do poder". Mais tarde, como sabemos, preferirá o termo "genealogia". Sua presença nessa passagem permite compreender que o problema do Estado é inscrito em um quadro onde ele aparece como um figura possível no enfrentamento das forças. Portanto, a noção clássica de soberania, assim como o evento histórico de centralização e controle da justiça e da economia, usualmente referidos como os traços distintivos do Estado moderno, não esclarecem propriamente o seu fundamento. Nos anos seguintes, Foucault irá aprofundar a problematização da relação entre Estado e soberania, assim como definição do papel do Estado a partir das relações de força.

\section{O Estado Soberano}

Em uma conferência pronunciada na Universidade Federal da Bahia, em 1976, Foucault afirma que o poder do Estado é essencialmente o poder jurídico, quer dizer, ele é essencialmente "representado pelo direito". Mas, logo em seguida, declara que "a unidade estatal é, no fundo, secundária com relação a esses poderes regionais e específicos, os quais vêm em primeiro lugar" (FOUCAULT, 1994a, p. 185). Ao retomar a clássica associação entre Estado e soberania, Foucault pretende chamar a atenção para o fato de ela ser insuficiente para explicar a natureza das relações de poder na sociedade moderna. Dizendo de outra forma, o Estado, instituição emblemática do poder soberano, é justamente aquilo que devemos "contornar", em favor das práticas sociais em que as relações de poder são exercidas. $\mathrm{O}$ poder soberano, identificado aqui com o poder de Estado, expressa-se sob a forma da lei e assim como a lei deixou de ser, na sociedade moderna, a forma privilegiada de exercício do poder, o Estado deixou de ser o lugar a partir do qual se organiza e estrutura o campo político ${ }^{5}$. Nenhuma narrativa totalizadora, englobante, afeita ao poder estatal, pode dar conta da "capilaridade" das relações de poder que se multiplicam pelas diversas camadas do tecido social. Apenas uma análise que contemple os "micro-poderes" e os mecanismos que o implementam será capaz de capturar a

\footnotetext{
${ }^{4}$ Para um estudo recente sobre o sentido desse termo na analítica do poder, ver Candiotto (2016).

${ }^{5} \mathrm{O}$ Estado deixa de ser considerado como aquele que toma a iniciativa do poder, deixa de ser considerado o lugar "de elaboração dos mecanismos de poder a partir dos quais este se irradia e toma conta do corpo social" (LAGASNERIE, 2015, p. 7).
} 
lógica do jogo de forças que estrutura a vida política moderna. E por meio dessa análise - ou melhor, dessa analítica do poder - será possível colher na miríade das práticas sociais uma nova forma de poder que Foucault denominará de "disciplinar".

A respeito dessa forma de poder, é necessário ressaltar dois pontos: 1) O primeiro diz respeito ao tipo de saber que informa o poder disciplinar e que viabiliza seu exercício. Como é bem conhecido, esse poder não pode dispensar, para produzir seu efeitos de assujeitamento, a implementação de um conjunto de técnicas e a formação de determinados saberes, dentre eles os que convencionamos chamar de "ciências humanas". Ao invés de garantirem o avanço em direção a uma sociedade mais civilizada, essas ciências, na perspectiva de Foucault, oferecem o saber imprescindível para intensificar as formas de dominação. 2) O segundo ponto, decorrente do primeiro, diz respeito à relação entre o poder soberano e o poder disciplinar e, para explorar esse tema, vou me servir de uma história contada por Foucault em seu curso de 1973-1974, O poder psiquiátrico. Na verdade, trata-se de uma cena que se passou em 1788 na Inglaterra, quando o país era governado pelo rei Jorge III. E é justamente esse rei um dos principais personagens dessa cena. O rei, lembra Foucault, "perdeu a cabeça", isto é, enlouqueceu e, por esse motivo, foi isolado em um quarto onde será totalmente subjugado ao poder de seu médico. Quem descreve a cena é Pinel, citado por Foucault:

Um monarca entra em mania e, para tornar sua cura mais pronta e mais sólida, não se faz nenhum restrição às medidas de prudência daquele que o dirige; por conseguinte, todo o aparelho da realeza se desvanece, o alienado, afastado da família e de tudo que o rodeia, é relegado a um palácio isolado e encerrado sozinho em um quarto cujo chão e cujas paredes são forradas de colchões para que ele fique impossibilitado de se ferir. Aquele que dirige o tratamento the declara que ele não é mais soberano, que deve, dali em diante, ser dócil e submisso. Dois de seus antigos pajens, da Estatura de Hércules, são encarregados de atender às suas necessidades e prestar-lhe todos os bons ofícios que sua condição exige, mas também de convencê-lo de que ele está sob a inteira dependência deles e de que doravante deve obedecer-lhes. Eles observam com ele um tranquilo silêncio, mas em todas as ocasiões fazem com que sinta o quanto lhe são superiores em força. Um dia, o alienado, em seu fogoso delírio, recebe duramente seu ex-médico que o vem visitar, e o cobre de dejetos e imundícies. Um dos pajens entra imediatamente no quarto sem dizer nada, agarra pela cintura o delirante, também reduzido a um estado de sujeira repugnante, derruba-o numa pilha de colchões, despe-o, limpa-o com uma esponja, troca suas roupas e, olhando para ele com altivez, afasta-se logo em seguida e volta para seu lugar. Lições assim, repetidas a intervalo durante alguns meses e secundadas por outros meios de tratamento, produziram uma cura sólida e sem recaída (FOUCAULT, 2006, p. 26).

A cena descreve, do ponto de vista de Foucault, uma "descoroação" do rei, uma "dessacralização", enunciada claramente na passagem em que se 
diz que "todo o aparelho da realeza desvanece" (FOUCAULT, 2006, p. 27). Como quer que seja, trata-se de sua deposição de seu lugar de poder. E o que opera essa deposição? Ora, Foucault acredita que ela é realizada não por um outro soberano, mas justamente por um outro poder. "A loucura do rei Jorge, diz ele, o faz cair sob um poder que é de um tipo totalmente diferente do da soberania e que, creio, se opõe a ela termo a termo". Foucault vai resumir essa mudança da seguinte maneira:

Não se trata, por conseguinte, da queda do poder soberano sob outro poder soberano, mas da passagem de um poder soberano, que foi decapitado pela loucura que se apossou da cabeça do rei e foi descoroado por essa espécie de cerimônia que indica ao rei que ele não é mais soberano, para outro poder. Pois bem, no lugar desse poder decapitado e descoroado se instala um poder anônimo múltiplo, pálido, sem cor, que é, no fundo, o poder que chamarei de disciplina. Um poder de tipo soberania é substituído por um poder que poderíamos dizer de disciplina, e cujo efeito não é em absoluto consagrar o poder de alguém, concentrar o poder num indivíduo visível e nomeado, mas produzir efeito apenas em seu alvo, no corpo e na pessoa do rei descoroado, que deve ser tornado 'dócil e submisso' por esse novo poder (FOUCAULT, 2006, p. 28).

É verdade que Foucault vai mitigar a força dessa distinção aparentemente estanque entre os dois tipos de poder, dizendo mais tarde que o "sistema das leis" convive com o da disciplina, e é mesmo operado por ela a partir do momento em que o direito funcionar na chave da norma. O que importa salientar é que a deposição do rei Jorge coincide com a deposição do Estado como agente político privilegiado na sociedade moderna. De nosso ponto de vista, o que Foucault faz nessa passagem poderia ser chamado de uma "crítica do Estado" que consiste, basicamente, em mostrar que a perda do protagonismo político do Estado se explica pelas profundas mudanças sociais e econômicas que tiveram lugar a partir do final do século XIX. Apenas a título de exemplo, vale lembrar que Foucault insistirá em vincular fortemente o advento do capitalismo ao surgimento do poder disciplinar. Essa "crítica" é sobretudo negativa: não se trata de tomar o Estado ele mesmo como objeto de exame, mas de deslocar o eixo da investigação e, ao mesmo tempo, colocar em xeque as teorias que lhe conferiam centralidade. Nunca é demais lembrar que, para Foucault, esse deslocamento, antes de ser uma decisão teórica, corresponde ao que acontece na realidade política. De fato, os dispositivos disciplinares, suas instituições e mecanismos, transcendem, ultrapassam o quadro institucional do Estado. Ora, o que nos parece fundamental é a consequência teórica que vai resultar daí: o Estado não será, para Foucault, um princípio de explicação do fenômeno político. Pelo contrário, ele será um fenômeno a se explicar (SKORNICKI, 2015, p. 53). Nessa etapa de sua genealogia isso ainda não está claramente formulado. Será preciso esperar o curso de 1978, Segurança, território, população. Mas antes de ir a esse curso, gostaríamos de complementar o que acabamos de afirmar recorrendo a uma passagem 
do curso de 1976, Em defesa da sociedade, quando Foucault faz referência à morte de Franco. Em certa medida, essa passagem replica a cena descrita em $O$ poder psiquiátrico.

Na aula de 17 de março de 1976, Foucault estabelece as distinções (que serão retomadas na parte final de $A$ vontade de saber) entre poder disciplinar e biopoder, mas também entre este último e o poder soberano. Essas diferenças são claras quando está em jogo a relação entre o poder e o direito de matar. Como é bem sabido, o poder soberano é aquele exercido sob a forma do "deixar viver e fazer morrer", ao passo que o biopoder é exercido como "fazer viver e deixar morrer". De um lado, o poder se manifesta da maneira mais visível quando mata; de outro lado, temos um poder que, ao se encarregar da promoção da vida, deixa a morte em uma zona de sombra. Foucault não deixará de assinalar que esses dois poderes se articulam, de modo que o Estado da biopolítica também deverá, de algum modo, exercer o poder soberano de matar (é o problema do racismo). Na perspectiva de Foucault, a partir do século XIX o biopoder irá sobrepor-se ao poder soberano. Foucault recorda então o exemplo de Franco, que havia morrido alguns meses antes dessa aula:

Para simbolizar tudo isso, tomemos, se vocês quiserem, a morte de Franco, que é um evento muito interessante pelos valores simbólicos que ele faz atuar, pois que morria aquele que tinha exercido o direito soberano de vida e de morte com a selvageria que vocês conhecem, o mais sangrento de todos os ditadores, que tinha feito reinar absolutamente, durante quarenta anos, o direito soberano de vida e de morte e que, no momento mesmo em que vai morrer, entra nessa espécie de novo campo do poder sobre a vida que consiste não somente em organizar a vida, não somente em fazer viver, mas finalmente em fazer viver o indivíduo além de sua morte. E, por um poder que não é simplesmente proeza científica, mas exercício efetivamente desse biopoder político que foi implementado no século XIX, fazemos tão bem as pessoas viverem que conseguimos fazê-las viver no momento mesmo em que deveriam, biologicamente, estar mortas há muito tempo. É assim que aquele que tinha exercido o poder absoluto de vida e de morte sobre centenas de milhares de pessoas, caiu sob o golpe de um poder que organizava de tal modo a vida, que considerava tão pouco a morte, que não se deu conta de que estava já morto e que se o fazia viver após sua morte. Creio que o choque entre esses dois sistemas de poder, o da soberania sobre a morte e o da regularização da vida, se encontra simbolizado nesse pequeno e alegre evento (FOUCAULT, 1997, p. 221).

A imagem de Franco mantido vivo durante meses em um hospital guarda semelhanças evidentes com a do rei Jorge III preso no quarto acolchoado. Em ambos os casos, temos o soberano deposto pelo aparecimento de um poder que, se não o anula ou o elimina, o envolve e o articula em um jogo de forças que o transcende. No momento crucial, no momento de crise (a loucura, a morte) aparece a verdade de um poder que tornou-se impotente, um poder cuja sobrevivência não depende mais dele. Por conseguinte, 
define-se nesse contexto o destino do Estado moderno. Mas nunca é demais insistir que Foucault, ao chamar a atenção para essa "deposição do Estado", não perde de vista o fato de que o Estado continuou a desempenhar uma função importante, embora como instância "secundária", o que é o mesmo que dizer (embora Foucault não o formule nesses termos) que a noção de soberania perdeu seu sentido originário, tornou-se uma expressão vazia, visto que o Rei (o Estado) não detém mais a supremacia política. Obviamente, o poder soberano não desapareceu, como não cansa de nos alertar Foucault. Mas o soberano, em sua acepção clássica, sai de cena a partir do momento em que o Estado se encontra a serviço de mecanismos de poder que não encontram nele sua origem, que são elaborados em outra parte, de acordo com estratégias e interesses específicos. É exatamente o que Foucault mostra em Vigiar e punir: os mecanismos disciplinares não poderiam encontrar sua notável disseminação nem sua aplicação sobre o corpo social se não fosse o intermédio da ação do Estado. E é justamente esse fato que revela a ilusão de que o Estado disporia de plena autonomia frente às forças sociais com as quais se defronta.

\section{O Estado Governamental}

A partir do momento em que inicia o exame do problema da governamentalidade, no curso de 1978, Segurança, território, população, Foucault amplia seu horizonte investigativo, concedendo atenção aos fenômenos políticos de maior escala concernentes à vida da população. Isso o obriga a colocar em nova perspectiva as noções de poder disciplinar e de biopoder. E, efetivamente, Foucault proporá, se não sua reformulação, ao menos seu rearranjo em um quadro desenhado pela questão da governamentalidade. Por exemplo, veremos nas primeiras aulas do curso uma tentativa de esquematização dos tipos de poder na forma de "sistema da lei", "sistema disciplinar" e "sistema de segurança" (FOUCAULT, 2004a, p. 13). Esses sistemas, acredita Foucault, não são excludentes nem contínuos, mas articulam-se uns com os outros de acordo com uma forma predominante de racionalidade política. Essa racionalidade se manifesta claramente no sistema de segurança, que será o eixo a partir do qual os demais irão se articular. Valeria a pena, para nossos propósitos, dirigir nossa atenção para o que especifica essa racionalidade política e como ela pôde determinar as interrelações das diversas tecnologias de poder. Acreditamos que essa é a via que nos conduz à questão do Estado.

Ora, o que especifica a racionalidade política moderna é justamente a noção que acabamos de evocar, isto é, a governamentalidade. Boa parte do curso de 1978 será dedicada à genealogia das práticas de governo, o que levará Foucault a recuar enormemente sua pesquisa, partindo da cultura 
antiga hebraica, passando pelos gregos, pelo cristianismo primitivo, pela patrística e pela Idade Média. E sob a égide do que ele denomina de "poder pastoral" que serão compreendidas as várias formas de "condução dos homens" ou, ainda, as técnicas de governo. O Estado moderno, que surge no século XVI, tem então sua história atrelada a essas técnicas. E aí começa a aparecer a novidade no tratamento que Foucault dará ao Estado. Isso porque a arte de governar moderna, embora não coincida totalmente com o Estado, não pôde deixar de mobilizá-lo, de ativá-lo como um elemento muito importante.

Para entender melhor esse fenômeno é preciso colocar em evidência uma tese de longo alcance, quer dizer, uma tese geral acerca da natureza do poder no mundo ocidental. A criação de um conjunto de técnicas de governo, de uma arte de governar, no interior do cristianismo exerceu uma influência profunda e duradoura sobre a experiência política ocidental. Não se trata, em absoluto, de dizer que houve uma espécie de teologização da política no final da antiguidade seguida de uma secularização ou desteologização no começo da modernidade. O que aconteceu é algo mais complexo. De pleno acordo com a visão de Peter Brown, Foucault acredita que a conversão do Império Romano ao Cristianismo remodelou a concepção de poder no Ocidente, o que pode ser apreendido se tivermos em mente a incorporação das técnicas de governo individual pelo poder político. Originalmente distintos e separados, poder religioso e poder político vão convergir, mas não na forma de uma teologia política e sim no engendramento de uma arte de governar que tem por função precípua conduzir a conduta (BÜTTGEN, 2007). Na esfera religiosa, essa condução da conduta concerne à alma, ao passo que, no âmbito do Estado, interessa conduzir os seres humanos em geral para a consecução de determinados fins.

A convergência entre poder político e religioso, na forma da utilização pelo poder público de uma tecnologia pastoral, marcará a época moderna e, consequentemente, estará no próprio fundamento do Estado moderno. Dizendo de outra forma, o Estado moderno é, por definição, o Estado de governo, o Estado governamental e governamentalizado, cuja função maior é gerir a vida de uma população, mas também promovê-la na escala individual. Não é difícil ver aqui uma notável mudança na maneira de abordar o Estado. Como vimos, até 1978 Foucault identificava o poder do Estado com o poder soberano. $\mathrm{O}$ que vemos agora é o reconhecimento de que o Estado moderno é uma realidade complexa, desempenhando papéis diversificados na realidade política. Se Foucault jamais vai deixar de vinculá-lo à noção de soberania, passará a defender, por outro lado, que, malgrado as teorias jurídico-políticas dos séculos XVII e XVIII, o Estado moderno é essencialmente um Estado de governo ${ }^{6}$. Mais ainda, reatando com o que havia avançado no curso sobre a sociedade punitiva

\footnotetext{
${ }^{6}$ A respeito, ver Jean Terrel (2010, p. 65-84).
} 
(em 1973), Foucault entenderá que o Estado soberano caracterizava o Estado medieval. No final da aula de 01 de fevereiro de 1978, definindo o que entende por "governamentalidade", Foucault não deixa dúvidas a respeito dessa natureza específica do Estado moderno. Nesse contexto, a governamentalidade é, em primeiro lugar, um conjunto de "instituições, procedimentos, análises e reflexões, cálculos e táticas que permitem exercer uma forma complexa e específica de poder"; em segundo lugar, é uma "tendência", uma "linha de força", atuante em todo o Ocidente, que levou à preeminência de uma forma de poder, "o poder de governo", sobre as demais, como a soberania e a disciplina. E essa "tendência" não se impôs sem o desenvolvimento de uma série de aparelhos específicos e de determinados saberes. Por fim, a governamentalidade é também “o processo, ou antes, o resultado do processo pelo qual o Estado de justiça da Idade Média, que se transformou, nos séculos XV e XVI, no Estado administrativo, foi pouco a pouco 'governamentalizado' " (FOUCAULT, 2004a, pp. 111-2). Convém, portanto, frisar essa distinção entre Estado soberano e Estado governamental, pois ela assinala, sem ambiguidades, o novo posicionamento de Foucault.

O que significa, concretamente, o Estado moderno assumir o encargo de governar deve ficar claro pela referência ao gerenciamento da vida da população e do indivíduo. Para levar a cabo essa tarefa, o Estado deverá colocar em funcionamento uma série de dispositivos, sobretudo os chamados "dispositivos de segurança", aos quais já fizemos alusão. Mas não apenas ele: também a tecnologia disciplinar será amplamente utilizada, o que permite compreender o modo pelo qual irá chegar até nós a técnica cristã do pastorado. E, por fim, o sistema jurídico também será integrado no conjunto das técnicas governamentais, pois sem o enquadramento legal as demais tecnologias encontram grandes dificuldades em sua implementação. Isso já é o suficiente para colocar a genealogia do Estado de Foucault à grande distância das concepções jurídicas de Estado, assim como da tradição do marxismo. Com efeito, no que concerne a este último, o Estado governamental não pode ser reduzido a um instrumento de dominação de classe; antes, ele envolve um conjunto de tecnologias cuja aplicação resulta dos confrontos, das disputas no interior do Estado ou, ainda, o Estado é o resultado dessas disputas entre as forças; impossível reduzi-lo, portanto, seja a um instrumento seja a um efeito das relações econômicas. O Estado, dirá Foucault, é um modo de se fazer, é uma "maneira de governar" (FOUCAULT, 2004a, p. 253).

Mas é uma maneira de governar que reflete sobre si mesma, o que nos permite voltar ao tema da racionalidade política. O Estado, para Foucault, é tanto uma prática política quanto um discurso político. E qual é esse discurso, essa racionalidade política do Estado moderno? Mais uma vez passando ao largo da tradição da filosofia política, Foucault vai encontrar a primeira formulação dessa racionalidade nas chamadas doutrinas da razão de Estado. Incluindo 
uma notável gama de pensadores (Botero, Palazzo, Naudé etc.), os autores da razão de Estado construíram o arcabouço teórico capaz de abarcar uma nova realidade política: o próprio Estado. Apesar das fortes divergências que os separam, todos defendem a necessidade de uma "ciência do Estado" cuja eficácia depende do conhecimento dos elementos que o compõem, isto é, não somente os homens, mas as relações que estabelecem entre si e com as "coisas". E por "coisas" é preciso entender os recursos do Estado, suas riquezas, mas também sua geografia, seus elementos naturais. Não ficam de fora também as atividades que os cidadãos realizam e os meios que as viabilizam, especialmente as trocas, a produção e a circulação de bens. A incumbência das doutrinas da razão de Estado é assegurar àqueles que exercem o poder o domínio verdadeiro sobre essa realidade, de modo que possam garantir sua conservação e aumento, como diria Botero.

Naturalmente, o saber sobre o Estado é, quando comparado ao discurso filosófico tradicional, de outra ordem. Não está em questão refletir sobre os fundamentos do Estado, sobre os princípios que conferem legitimidade ao exercício do poder, muito menos sobre a natureza do poder soberano. O que importa é recolher, no nível empírico das coisas do Estado, um conhecimento que permita uma intervenção sobre ele. Mas a razão de Estado faz mais do que isso: ela também deve esclarecer sob quais condições o conhecimento das coisas deve ser utilizado, pois é o que assegura sua eficácia. Dizendo de outra forma, a razão de Estado tem por tarefa formular um "arte do governo", uma técnica que, fundamentada no conhecimento do objeto Estado, permita a consecução de seus fins. E que fins são esses? A esse respeito, Foucault, baseando-se em Palazzo, afirma o seguinte:

O fim da razão de Estado é o próprio Estado e, se há algo como uma perfeição, como uma realização (bonheur), como uma felicidade, serão sempre aquelas do próprio Estado. Não há último dia. Não há ponto derradeiro. Não há algo como uma organização temporal unida e final (FOUCAULT, 2004a, p. 264).

Essa passagem é emblemática porque explicita o fechamento da razão de Estado sobre uma realidade que passa a ser autorreferente. Em clara ruptura com a racionalidade política medieval, que ainda preconizava a realização da vida humana em um fim ultraterreno, e submetia o poder temporal à consecução desse fim, a razão de Estado está liberada da teleologia, da escatologia e da crença na possibilidade de um poder universal que submeta os diversos Estados ao domínio de um único senhor. A racionalidade política estatal se depara com uma realidade política fragmentada, na qual os Estados competem entre si em um jogo de forças que deixa sempre aberta a possibilidade da guerra, ao mesmo tempo em que é ordenada pela ideia de equilíbrio ${ }^{7}$. Nesse sentido, será imprescindível, no contexto da razão de

\footnotetext{
${ }^{7}$ A respeito, ver a aula de 22 de março de 1978 (FOUCAULT, 2004a, p. 293-318).
} 
Estado, o desenvolvimento de um dispositivo diplomático-militar para lidar com os problemas de ordem externa. Mas será necessária também a colocação em prática de um dispositivo que, respondendo às questões interestatais, seja capaz de "majorar", de aumentar as forças internas do Estado. De acordo com Foucault, esse é o dispositivo de "polícia" (FOUCAULT, 2004a, pp. 319-40).

A partir daí, há dois aspectos do Estado que essa genealogia coloca à luz: por um lado, o Estado aparece em um sentido que poderíamos chamar de "objetivo", isto é, ele corresponde a um recorte na realidade política, um domínio de intervenção para o poder público. Mas ele é ainda um princípio ativo, na medida em que esse campo de intervenção política requer a criação de um "aparelho administrativo" (FOUCAULT, 2004a, p. 280). Embora esse ponto não seja desenvolvido em sua análise, parece-nos que Foucault integra em sua genealogia do Estado moderno o tema clássico da burocracia8: o Estado moderno, Estado administrativo desde seu surgimento, não pode ser compreendido plenamente quando retemos apenas seu aspecto jurídico. Esta lição, repetida ao longo de todo o curso, fica ainda mais clara. O Estado, como domínio da realidade, tem como contrapartida o surgimento de algo totalmente inédito: um corpo técnico, composto por agentes encarregados não somente de fazer cumprir as ordens do soberano ou coletar as taxas e impostos, mas que seja "ao mesmo tempo um aparelho de saber, aí ainda como dimensão essencial para o exercício do poder" (FOUCAULT, 2004a, p. 280). O Estado moderno, portanto, pode ser tomado como um dispositivo de saber/poder. Mas aqui já não falamos mais do Estado como "instância do real", e sim do estado como agente político, ou melhor, como lugar a partir do qual as relações de poder serão exercidas. Esse passo parece fundamental porque evidencia a novidade das análises de Foucault em 1978. Se até então a analítica do poder "passava por detrás" da instituição do Estado - e, em certa medida, isso também é feito na parte inicial do curso de 1978 - ela reconhece agora a necessidade de colocar no primeiro plano o fato do Estado desempenhar um papel fundamental no âmbito das tecnologias de poder. Definitivamente, o Estado deixa de ser considerado somente o locus da soberania para transformar-se em um nódulo no qual se articulam as relações de poder no contexto da governamentalidade. Por isso Foucault pode dizer que o estado é um "efeito da governamentalidade" (FOUCAULT, 2004a, p. 280). Ora, isso significa que não podemos em absoluto tomar o Estado como uma substância ou um universal que contivesse em si mesmo seu princípio de desenvolvimento. O Estado moderno não é a causa nem a consequência da existência de uma série de instituições e de aparelhos, como a fiscalidade,

\footnotetext{
${ }^{8}$ A. Skornicki chega à mesma conclusão: “O dispositivo governamental moderno, tal como descrito por Foucault, não corresponde a nada menos do que à gênese da dominação legal-racional, quer dizer, ao monopólio político de um agrupamento complexo dotado de uma administração burocrática" (SKORNICKI, 2015, p. 213). Evidentemente, o cotejamento com Weber a esse propósito seria bastante esclarecedor.
} 
o exército, a própria estrutura da soberania e a dimensão pública. O Estado é aquilo que se faz quando, no interior dessas instituições, graças a elas, é possível exercer o poder como uma forma de governo. Por isso, Foucault insiste em definir o Estado como uma "prática refletida" e não como um objeto preexistente a essas práticas e que nelas realizaria uma espécie de evolução: "Não podemos falar de um Estado-coisa como se fosse um ser se desenvolvendo a partir de si mesmo e se impondo por uma mecânica espontânea, como automática, aos indivíduos. O Estado é uma prática" (FOUCAULT, 2004a, p. 282). O Estado, como "prática refletida", remete tanto a um domínio de objetos, relações de coisas e pessoas, quanto a um domínio exclusivamente técnico, como arte de governar fundamentada em um conhecimento da realidade. A expressão "prática refletida" explicita essa dupla dimensão, o fazer e o conhecimento, a ação e a reflexão, o poder e o saber. Mas ainda é importante observar que, se o Estado moderno não é uma decorrência necessária de um conjunto de instituições que o antecedem, então ele não possui nenhuma essência ${ }^{9}$ e seu aparecimento produz uma modificação no campo de experiências onde ele surge:

O evento reflexivo, o conjunto de processos pelos quais o Estado efetivamente, em um momento dado, entrou na prática refletida das pessoas, a maneira pela qual o Estado, em um momento dado, tornou-se, para aqueles que governavam, para aqueles que aconselhavam os governantes, para aqueles que refletiam sobre os governos e ações dos governantes tal como a viam (...), essa maneira foi, seguramente, não o fator absolutamente determinante do desenvolvimento dos aparelhos de Estado que na verdade já existiam antes (...), mas foi absolutamente capital, penso, para que todos esses elementos entrassem no campo de uma prática ativa, concertada, refletida que foi precisamente o Estado (FOUCAULT, 2004a, p. 282).

Não é sem razão que Foucault irá também considerar o Estado uma "ideia reguladora", um princípio de inteligibilidade da razão governamental (FOUCAULT, 2004a, p. 294). À maneira da ideia reguladora kantiana, o Estado é então esvaziado de qualquer conteúdo próprio; assim como a ideia não contém qualquer elemento empírico - servindo unicamente para organizar, unificar, guiar os conceitos do entendimento - o Estado é tão somente o princípio de inteligibilidade que permite unificar uma variedade de elementos já dados. Essa unidade consiste no estabelecimento de uma certa relação entre eles, de modo que passam a ser entendidos como parte de um todo: o soberano, a lei, o magistrado, as riquezas, os habitantes de um território são concebidos como elementos do Estado (FOUCAULT, 2004a, p. 294). E não apenas o Estado é "ideia reguladora": ele também

\footnotetext{
${ }^{9}$ A esse respeito, é conveniente lembrar que o "método" foucaultiano é uma espécie de "nominalismo histórico", como dizia Paul Veyne (2008), no qual está em questão "fornecer descrições históricas de como práticas teoréticas e institucionais deram origem a objetos de uma certa classe, tais como a economia, a loucura, a sexualidade ou o Estado" (WALTER, 2008, p. 103).
} 
funciona, na razão governamental, como objetivo, quer dizer, aquilo que "deve ser obtido no término das intervenções ativas dessa razão, dessa racionalidade. O Estado é o que deve estar no final da racionalização da arte de governar" (FOUCAULT, 2004a, pp. 294-5).

Dupla "natureza" do Estado que coloca em nova perspectiva o que Foucault havia apresentado até então. Por um lado, princípio de leitura do real da política e, por outro, finalidade da governamentalidade, o Estado torna-se o núcleo dessa forma de racionalidade política, operando como um grande princípio unificador: como "ideia reguladora", assegura uma ordem para a heterogeneidade dos elementos que o antecedem; como fim da razão governamental (o Estado como "imperativo"), ele dá o eixo e a direção para a ação política. Como vemos, o Estado não pode ser reduzido a sua dimensão institucional ${ }^{10}$. Ele assegura uma espécie de síntese que, sem eliminar as especificidades e as heterogeneidades de todos os elementos que compõem o domínio político, os mantém relacionados no interior de um mesmo quadro de referência. Em suma: "Governar racionalmente porque há um Estado e para que haja um Estado" (FOUCAULT, 2004a, p. 295).

\section{Considerações Finais}

Como pudemos ver, Foucault realizou um deslocamento em seu tratamento do problema do Estado, a partir do qual a "crítica do Estado" adquiriu um sentido novo. Se inicialmente o Estado deveria ser "contornado" para apreendermos a verdadeira natureza das relações de poder na sociedade moderna, agora ele é um tema obrigatório para compreendermos essas mesmas relações, a ponto de um comentador afirmar que "a genealogia do poder moderno torna-se insensivelmente aquela do Estado moderno" (SCORNICKI, 2015, p. 14). Afinal de contas, não é nesse sentido que ele vai dizer, em 1979, que “o fenômeno da estatização está no coração das

\footnotetext{
${ }^{10}$ À semelhança do que havia realizado em sua história da prisão, Foucault destaca o fato de que o Estado se efetiva inicialmente não como instituição, mas como uma forma de atuação do poder. Em cotejamento com a prisão, podemos esclarecer esse ponto retomando o início da quarta parte de Vigiar e punir: "A prisão é menos recente do que se diz quando se faz datar seu nascimento dos novos códigos. A forma-prisão preexiste à sua utilização sistemática nas leis penais. Ela se constituiu no exterior do aparelho judiciário, quando se elaboraram, por todo o corpo social, os processos para repartir os indivíduos, fixá-los e distribuí-los espacialmente, classificá-los, tirar deles o máximo de tempo, e o máximo de forças, adestrar seus corpos, codificar seu comportamento contínuo, mantê-los numa visibilidade sem lacuna, formar em torno deles um aparelho completo de observação, registro e notações, constituir sobre eles um saber que se acumula e se centraliza. A forma geral de uma aparelhagem para tornar os indivíduos dóceis e úteis, através de um trabalho preciso sobre seu corpo, desenhou a instituição-prisão, antes que a lei a definisse como a pena por excelência" (FOUCAULT, 1975, p. 267). Finalmente, não estaria em jogo, nas análises de Foucault, sobretudo a genealogia da forma-Estado?
} 
questões que tentei colocar" (FOUCAULT, 2004b, p. 79)? Mas ao redimensionar a questão do Estado na política moderna, a partir do curso de 1978, Foucault marca a diferença entre Estado e soberania, quer dizer, o Estado o interessa como "prática política" governamental, e não mais como a sede da soberania. Essa novidade no tratamento do Estado não pode ser compreendida senão quando referida à ampliação do horizonte investigativo de Foucault, quando passa a compreender o problema do poder como um fenômeno concernente à "conduta" e ao "governo". Contudo, precisamos reconhecer que há uma forte continuidade entre os dois momentos da análise de Foucault. Na verdade, a crítica à concepção jurídica do poder - que, no âmbito do Estado, é, basicamente, a crítica da noção de soberania - encontra prolongamento na genealogia da governamentalidade, uma vez que é reiterado o gesto que priva o Estado de seu atributo principal, historicamente reconhecido, isto é, a própria soberania. Em outras palavras, a analítica do poder anuncia, como observaram Dean e Villadsen (2016, p. 31), o "fim da forma transcendente do poder", em favor de um "reino da imanência", o que significa que o Estado é privado de sua forma de poder constitutiva, a soberania. Nesse sentido, Foucault conserva, até o fim de seus estudos acerca da governamentalidade política, uma posição fortemente contrária a toda tentativa de restituir ao Estado um papel central na política contemporânea. Levando isso em conta, não surpreende o fato das análises de Foucault darem azo às formas mais ou menos radicais de "anti-estatismo"11. No entanto - e por mais que em diversos momentos de sua trajetória acadêmica e de sua vida militante Foucault tenha se mostrado bastante crítico com relação às instituições políticas -, o escopo de seu trabalho não pode ser reduzido a uma demolição do Estado, nem do ponto de vista conceitual nem do ponto de vista da ação política. Se, como acabamos de afirmar, o Estado é um elemento incontornável na genealogia do poder moderno, ele apenas pode sê-lo na medida em que é transformado em um "dispositivo" nas relações de poder. Nesse sentido, a genealogia do poder termina por identificar uma nova "politização" do Estado, isto é, ela explicita que o Estado moderno é também um objeto de investimento político. Dizendo de outra forma, as relações de poder passam pelo Estado. Por conseguinte, as lutas políticas não podem dispensá-lo, não podem desconsiderar seu papel na definição do jogo político e na organização da vida social. Como lembra Skornicki (2015, p. 222), o próprio Foucault demonstrou que o Estado moderno é irredutível a um mero instrumento de dominação de classes, quer dizer, ele não é apenas o Estado burguês, mas é igualmente o Estado social, o Estado que se constitui a partir dos enfrentamentos políticos que atravessam o corpo social e que é, portanto, uma construção social. Sob esse prisma, ele não pode ficar de fora quando está em jogo a conquista dos direitos sociais e, sobretudo, a edificação da liberdade política.

\footnotetext{
${ }^{11}$ A respeito, ver sobretudo os capítulos 1 e 2 do livro de Dean e Villadsen (2016, p. 9-32).
} 
Estamos convencidos de que as análises de Foucault não são, em absoluto, incompatíveis com essa última visão do Estado moderno. Dizendo de outra maneira, acreditamos que o pensamento de Foucault, diferentemente do que vemos em certos trabalhos dos nouveaux philosophes ${ }^{12}$, coloca em xeque o anti-estatismo radical ${ }^{13}$. Em certa medida, sua genealogia do Estado moderno, como sugeriu Stephen Sawyer (2015, pp. 135-6), pode ser entendida como uma forma original de se repensar o papel do Estado na realidade política contemporânea ${ }^{14}$. Afinal de contas, se as relações de poder são sempre reversíveis, se o poder é "um nome que atribuímos a uma situação estratégica complexa em uma dada sociedade" (FOUCAULT, 1976, p. 123), então os "aparelhos", os mecanismos, dentre eles o Estado, podem ser utilizados para intensificar a dominação ou para amenizá-la em direção a uma forma de sociabilidade em que sejamos mais autônomos ou, ainda, para relembrarmos uma noção central no curso de 1978, toda conduta (entendida como condução) enseja uma contra-conduta, o que deixa indefinido o jogo da dominação. Foucault deixou pistas para pensar o Estado dessa maneira, como vemos nos seus estudos sobre as lettres de cachet, por exemplo. Ele nos mostra que a lógica da soberania pode, em determinados contextos, se inverter e o Estado soberano pode se constituir como "um prolongamento das forças que vêm de baixo" (FARGE e FOUCAULT, 2014). As lettres de cachet são exatamente um instrumento mobilizado pelas famílias no Antigo Regime para resolver o problema de sua "desordem interna" (FARGE e FOUCAULT, 2014, pp. 16-9). Por elas, o Estado entra no jogo das relações de poder que seus membros entretêm consigo mesmos e com a sociedade. E o Estado assegura uma espécie de "serviço público", solicitado pelos próprios súditos do rei. Mas é verdade que Foucault acredita que a demanda dessas cartas não é sinal de emancipação, ao contrário. Trata-se da penetração do "poder real soberano" no "cotidiano da vida", de modo que cada um pode "usar para si, para seus próprios fins e contra os outros, da enormidade do poder absoluto: uma espécie de colocação à disposição dos mecanismos da soberania, uma possibilidade dada a quem for hábil o bastante para aproveitá-la, de desviar seus efeitos a seu proveito" (FOUCAULT, 1994c, pp. 246-7). Contudo, o que importa assinalar é que esses procedimentos atestam a realidade do basculamento do poder do Estado pela sociedade para fins que poderiam, ao menos em princípio, ser emancipatórios. De nosso ponto de vista, esta é uma verdadeira possibilidade, no interior do pensamento de Foucault, de

\footnotetext{
${ }^{12}$ Por quem Foucault não deixou de demonstrar entusiasmo, especialmente por André Glucksman e seu livro La cuisinière et la mangeur d'hommes (1975). A respeito ver a entrevista de Foucault a Jacques Rancière, "Pouvoir et Stratégie" (FOUCAULT, 1994b), e também o livro de Serge Audier (2015).

${ }^{13}$ Afinal de contas, o anti-estatismo radical não seria uma forma de "fobia do Estado" que Foucault denuncia na aula de 01 de fevereiro de 1978 ?

${ }^{14} \mathrm{Na}$ mesma direção, mas em uma linha mais conservadora, seguem Dean e Villadsen, ao reconhecerem que o conceito de Estado não pode ser desconsiderado nas análises políticas e sociais (DEAN e VILLADSEN, p. 165-78).
} 
se conjugar liberdade política e poder público estatal. E esta possibilidade foi aberta por seus estudos sobre a governamentalidade. Após 1978, o problema da liberdade e do Estado será tratado de modo circunscrito na genealogia da governamentalidade liberal, tema do curso de 1979, O nascimento da biopolítica, quando Foucault colocará outra vez em questão nossa relação com o Estado. Mais especificamente, Foucault concederá novamente atenção à "fobia do Estado" que havia denunciado em 1978. Mas, nesse contexto, a "fobia do Estado" fornece o mote para colocar sob exame as práticas de governo liberais (e neoliberais), pois elas também se apoiam sobre essa desconfiança com respeito ao Estado (FOUCAULT, 2004b, p. 77). Se, em 1978, Foucault denunciava o anti-estatismo anarquista e marxista (FOUCAULT, 2004a, p. 112), em 1979 é o anti-estatismo liberal que está na mira, pois que ele integra o conjunto de estratégias que assegura essa forma específica de governamentalidade e, por conseguinte, de dominação. Como vemos, é por essa via "indireta" (FOUCAULT, 2004b, p. 78) que Foucault explicita a necessidade de redimensionar o papel do Estado se quisermos abrir a possibilidade de constituir formas mais livres de sociabilidade.

\section{Referências:}

AUDIER, Serge. Penser le néolibéralisme. Le moment néoliberal, Foucault et la crise du socialisme. Lormont: Le Bord de 1'Eau, 2015.

BALIBAR, Etienne. Lettre d'Etienne Balibar à l'Éditeur du Cours. In: FOUCAULT, Michel. Théorie et Institutions Pénales. Paris: EHESS/Gallimard/Seuil, 2015.

BÜTTGEN, Philippe. Théologie Politique et Pouvoir Pastoral. Annales. Histoire, Sciences Sociales, n 5, 2007.

CANDIOTTO, Cesar. Michel Foucault: As Lutas em Torno do Poder e a Dinástica do Saber. In: Kriterion. Vol. 57, no 135, 2016, pp. 659-675.

DEAN, Mitchell e VILLADSEN, Kaspar. State phobia and civil society. Stanford: Stanford University Press, 2016.

FARGE, Arlette e FOUCAULT, Michel. Le désordre des familles. Lettres de cachet des Archives de la Bastille au XVIII siècle. Paris: Gallimard, 2014 (2a edição).

FOUCAULT, Michel. Surveiller et punir. Naissance de la prison. Paris: Gallimard, 1975. FOUCAULT, Michel. Histoire de la sexualité 1. La volonté de savoir. Paris: Gallimard, 1976.

FOUCAULT, Michel. "Il faut défendre la société". Cours au Collège de France 19751976. Paris: Gallimard/Seuil, 1997.

FOUCAULT, Michel. Les Mailles du Pouvoir. In: Dits et écrits. Vol. IV.

Texto ${ }^{\circ}$ 297. Paris: Gallimard, 1994a.

FOUCAULT, Michel. Pouvoir et Stratégie. In: Dits et écrits. Vol. III.

Texto ${ }^{\circ}$ 218. Paris: Gallimard, 1994b. 
FOUCAULT, Michel. La Vie des Hommes Infâmes. In: Dits et écrits. Vol. III. Texto n ${ }^{\circ}$ 198. Paris: Gallimard, 1994c.

FOUCAULT, Michel. Le Jeu de Michel Foucault. In: Dits et écrits. Vol.

III. Texto $n^{\circ}$ 206. Paris: Gallimard, 1994d.

FOUCAULT, Michel. La Philosophie Analytique de la Politique. In:

Dits et écrits. Vol. III. Texto $\mathrm{n}^{\circ}$ 232. Paris: Gallimard, 1994e.FOUCAULT, Michel. Sécurité, territoire, population. Cours au Collège de France. 1977-1978. Paris: Gallimard/ Seuil, 2004a.

FOUCAULT, Michel. Naissance de la biopolitique. Cours au Collège de France 19781979. Paris: Gallimard/Seuil, 2004b.

FOUCAULT, Michel. O poder psiquiátrico. Trad. de E. Brandão. São Paulo: Martins Fontes, 2006.

FOUCAULT, Michel. Théorie et Institutions Pénales. Paris: EHESS/Gallimard/Seuil, 2015.

GLUCKSMANN, André. La cuisinière et la mangeur d'hommes. Paris: Seuil, 1975.

LAGASNERIE, Geoffroy de. Du Droit à l'Émancipation. Sur l'État, Foucault et l'Anarchisme. Inédito. 2015. Disponível em http://conversations.grand-angle-libertaire.net/seminaire-etape-n19-interrogations-sur-letat-foucault-et-lanarchisme. Último acesso: 10/11/2016.

LORENZINI, Daniele. A Filosofia Política à Prova do Ordinário. In: FONSECA, A. C. M.; GALANTIN, D. V e RIBAS, T. F. Políticas não identitárias. São Paulo: Intermeios, 2017, pp. 215-36.

SAWYER, Stephen. Foucault and the State. The Tocqueville Review, vol 36, nº 1, 2015.

SKORNICKI, Arnault. La grande soif de l'État. Foucault avec les sciences sociales. Paris: Les Prairies Ordinaires, 2015.

TERREL, Jean. Politiques de Foucault. Paris: PUF, 2010.

VEYNE, Paul. Foucault, sa pensée, sa personne. Paris: Albin Michel, 2008.

WALTER, Ryan. Reconciling Foucault and Skinner on the State: The Primacy of Politics? History of Human Sciences. Vol. 21, n 3, 2008.

Endereço do Autor:

Faculdade de Filosofia e Ciências Humanas.

Departamento de Filosofia, sala 4051

Av. Antônio Carlos, 6627

31270-901 Belo Horizonte - MG

heltonadverse@hotmail.com 